\title{
A COMPARTICIPAÇÃO COMO PRESSUPOSTO DE EFETIVIDADE DAS MEDIDAS ESTRUTURANTES DEFERIDAS LIMINARMENTE
}

\section{COPARTICIPATION AS ASSUMPTION OF EFFECTIVENESS OF STRUCTURAL INJUNCTIONS PRELIMINARILY GRANTED}

\author{
Vanessa Sousa Vieira ${ }^{1}$ \\ Fabiane Cristina de Almeida ${ }^{2}$
}

\section{RESUMO}

Decisões judiciais inexequíveis são inefetivas. Contudo, diuturnamente, operadores do direito são desafiados a buscar meios de cumprir determinações judiciais. Em se tratando da implementação de medidas estruturantes, esse desafio é agigantado. O Processo Constitucional Democrático pressupõe participação ativa de todos os sujeitos envolvidos na construção do provimento, pois a efetividade da decisão judicial, especialmente aquela que implementa medidas estruturantes, está intimamente ligada à comparticipação de todos os sujeitos processuais. Defende-se, assim, que o deferimento liminar de medida estruturante deve ser precedido de oitiva da parte contrária, de modo a permitir a prolação de decisões efetivas.

Palavras-chave: Novo código de processo civil, Medidas estruturantes, Liminar, Comparticipação, Efetividade

\begin{abstract}
Unenforceable judgments are ineffective. However during the daytime, law operators are challenged to find ways to comply with court orders. In the case of the implementation of structural measures, this challenge is gigantic. The Democratic Constitutional process requires active participation of all those involved in the construction of the provision,

because the effectiveness of the court decision, especially one that implements structural measures, is closely linked to reimbursement of all procedural subjects. It is argued, therefore, that the structural measure preliminary approval should be preceded by hearing the opposing party, to allow the delivery of effective decisions.
\end{abstract}

Keywords: New code of civil procedure, Structural injunctions, Preliminary decisions, Participation, Effectiveness

\footnotetext{
${ }^{1}$ Pós Graduada em Direito Processual pela Pontifícia Universidade Católica de Minas Gerais - PUC/MG, Minas Gerais, (Brasil). Titular da Gerência de Expediente Legislativo da Prefeitura Municipal de Belo Horizonte, Minas Gerais, (Brasil). E-mail: vanessavieira@outlook.com.br

${ }^{2}$ Pós Graduada em Direito Processual pela Pontifícia Universidade Católica de Minas Gerais - PUC/MG, Minas Gerais, (Brasil). Professora da Escola Superior de Advocacia e Advogada Autônoma, Minas Gerais, (Brasil). Email: fabianealmeida.adv@outlook.com
} 


\section{INTRODUÇÃO}

A efetividade dos mandamentos judiciais é preocupação que permeia todo o universo jurídico. Nada é mais frustrante para os que lidam com o direito que a impossibilidade de cumprimento satisfatório de decisão que declara direitos e determina sua observância.

O presente estudo apresenta caso demonstrativo da dificuldade de implementação de liminares deferidas previamente à oitiva da parte contrária, sobretudo em processos que envolvem a litigância do interesse público e, logo, decisões sobre medidas estruturantes.

Após a apresentação do caso paradigma, que trata da judicialização da saúde, são apontadas as novas diretrizes que norteiam os procedimentos do Novo Código de Processo Civil (NCPC), exaltando-se seu viés comparticipativo na construção de provimentos efetivos.

Considerando a importância da instauração do contraditório como meio de se franquear às partes a participação no processo, são expostas, brevemente, as inovações trazidas no novo texto legislativo, no que concerne à oitiva da parte contrária previamente à concessão de medidas liminares. Em seguida, a comparticipação é apresentada como medida de efetividade de decisões proferidas em processos democraticamente estruturados.

A partir da problemática concernente à efetividade de decisões judiciais, especificamente as medidas liminares concedidas em processos que envolvam a litigância de interesse público, ressaltar-se-á o quão imprescindível é a comparticipação na viabilização de cumprimento de decisão judicial. Afinal, de nada adianta uma Jurisdição desatrelada da efetividade. E o processo democrático e constitucional é a ponte que liga uma à outra.

Para tanto, foi feita uma pesquisa bibliográfica, jurisprudencial e também de textos jornalísticos sobre o tema, além de estudo dogmático acerca da matéria no NCPC.

\section{EXEMPLO RECENTE DE IMPLEMENTAÇÃO DE MEDIDA ESTRUTURANTE PELO PODER JUDICIÁRIO PAULISTA}

Em 2015 foi divulgado na mídia brasileira o resultado dos estudos relacionados à substância "fosfoetanolamina", que, supostamente, seria capaz de curar o câncer. 
Pesquisadores da Universidade de São Paulo (USP) - Instituto de Química de São Carlos vêm desenvolvendo estudos a esse respeito desde 1980, sob coordenação do professor Gilberto Orivaldo Chierice, hoje aposentado.

A partir da possibilidade de ação anticancerígena, a "fosfoetanolamina" passou a ser sintetizada em laboratório, no Instituto de Química de São Carlos.

\begin{abstract}
Embora a terapia atual para o câncer dependa principalmente do uso de cirurgia, irradiação e quimioterapia, a evolução na compreensão da biologia da transformação maligna e das diferenças no controle da proliferação e morte da célula normal e cancerosa, proporcionou a descoberta de novos alvos possíveis para o tratamento do câncer. É provável que novas terapias, como no caso da fosfoetanolamina sintética, desenvolvida pelo nosso grupo, venham a substituir ou combinar-se às já existentes, aumentando a eficácia do tratamento e diminuindo a incidência de efeitos colaterais (MENEGUELO, 2002, p. 113).
\end{abstract}

Chierice coordenou durante mais de vinte anos pesquisas científicas no intuito de comprovar a eficácia da substância mencionada. De acordo com Renato Meneguelo:

\begin{abstract}
Neste trabalho, a fosfoetanolamina sintética obtida a partir de um processo de latenciação mostrou-se eficaz inicialmente "in vitro" na capacidade de inibir o crescimento de células de melanoma ${ }^{3}$ B16F10, expostas às várias concentrações desse composto.
\end{abstract}

\title{
$[\ldots]$
}

Comparando sua atividade inibitória "in vitro" a outros quimioterápicos, usualmente administrados em pacientes portadores de cânceres, como o paclitaxel, inibidor específico da fase $\mathrm{G} 2 / \mathrm{M}$ ou o etoposideo, inibidor de topoisomerases tipo II, a fosfoetalonamina sintética se mostrou cerca de 130 vezes mais eficaz em sua atividade inibitória que as drogas comerciais, demonstrados neste mesmo estudo (MENGUELO, 2002, p. 106-107).

Tendo em vista a divulgação dos resultados obtidos em laboratório, inúmeras pessoas começaram a procurar os pesquisadores da Universidade, para obterem cápsulas da substância. De acordo com matérias divulgadas, como a do Marcelo Toledo (2015), "nos últimos dois dias, filas se formaram na universidade em busca da droga. Alguns creem que essa pode ser a última chance de evitar a morte dos doentes".

Alguns pacientes relataram que receberam cápsulas da substância diretamente dos pesquisadores da Universidade, em São Carlos. Tendo em vista o aumento da procura pela droga, entregue gratuitamente, ela parou de ser fornecida, com base na Portaria IQSC 1.389/2014 (UNIVERSIDADE DE SÃO PAULO, 2014), que dispõe ser imprescindível a 
apresentação de licenças e registros expedidos pelos órgãos competentes - Ministério da Saúde (MS) e Agência Nacional de Vigilância Sanitária (ANVISA) - à Diretoria do Instituto de Química de São Carlos, para que seja extraído, produzido, fabricado, transformado, sintetizado, purificado, fracionado, embalado, reembalado, armazenado, expedido e distribuído qualquer medicamento ou insumo farmacêutico nas dependências da USP.

Em nota divulgada, a instituição de ensino esclareceu que:

Essa substância não é remédio. Ela foi estudada na USP como um produto químico e não existe demonstração cabal de que tenha ação efetiva contra a doença: a USP não desenvolveu estudos sobre a ação do produto nos seres vivos, muito menos estudos clínicos controlados em humanos. Não há registro e autorização de uso dessa substância pela Anvisa e, portanto, ela não pode ser classificada como medicamento, tanto que não tem bula.Além disso, não foi respeitada a exigência de que a entrega de medicamentos deve ser sempre feita de acordo com prescrição assinada por médico em pleno gozo de licença para a prática da medicina. Cabe ao médico assumir a responsabilidade legal, profissional e ética pela prescrição, pelo uso e efeitos colaterais - que, nesse caso, ainda não são conhecidos de forma conclusiva - e pelo acompanhamento do paciente (UNIVERSIDADE DE SÃO PAULO, 2015).

Diante da postura da Universidade, centenas de ações judiciais foram propostas com o intuito de obrigá-la a fornecer as cápsulas da "fosfoetanolamina" sintética, produzidas em laboratório, para pacientes portadores de câncer.

Exemplo disso é a ação cominatória no 1008889-52.2015.8.26.0566 (SÃO PAULO, 2015), proposta por um paciente diagnosticado com câncer de pulmão (neoplasia maligna) em face do Estado de São Paulo e da USP - Campus São Carlos, relatando já ter tido acesso à substância, mas em quantidade insuficiente para completar o tratamento. Em vista disso e relatando resultado parcial satisfatório, requereu a concessão de antecipação de tutela para compelir os réus a fornecerem o produto.

Na primeira decisão, o juízo da Vara da Fazenda Pública de São Carlos concedeu a antecipação de tutela, sem oitiva dos réus, com base no direito à vida e à saúde, sendo este último dever do Estado, por meio de entidades públicas. Considerou ultrapassado o fato de a substância não ter sido testada, aprovada e registrada como medicamento junto ao MS e à ANVISA, diante de ressalva contida no art. $24^{4}$ da Lei 6.360/1976 (BRASIL, 1976), que trata da Vigilância Sanitária a que ficam sujeitos os medicamentos, as drogas, os insumos farmacêuticos e correlatos, cosméticos, saneantes e outros produtos. 
Foi, então, deferida a antecipação parcial dos efeitos da tutela, de forma a determinar a disponibilização da "fosfoetanolamina" sintética pelos réus, no prazo de cinco dias, em quantidade suficiente para garantir o tratamento do autor, sob pena de multa diária no valor de R \$ 1.000,00 (um mil reais). Além disso, suspendeu a Portaria n. 1.389/2014 (UNIVERSIDADE DE SÃO PAULO, 2014).

Contra essa decisão a USP interpôs agravo de instrumento pedindo a suspensão da tutela antecipada concedida e requerendo efeito suspensivo liminar expansivo a todas as liminares da mesma natureza concedidas, ao argumento de que a substância não é um medicamento, posto não haver qualquer registro dela perante os órgãos competentes. Foi concedida a tutela recursal antecipada pelo Presidente do Tribunal de Justiça de São Paulo, Desembargador José Renato Nalini, nos autos n. 2194962-67.2015.8.26.0000 (SÃO PAULO, 2015), de modo que a decisão anterior foi suspensa, bem assim estariam todas as outras proferidas em processos que tratassem da questão, mediante o encarte delas nos autos recursais.

A questão chegou ao Supremo Tribunal Federal (STF), por meio de provocação de outro jurisdicionado, referente a outros autos e está sendo discutida, sendo relator o Ministro Edson Fachin. O recorrente obteve liminar favorável a si, tendo-lhe sido assegurado acesso à substância em quantidade suficiente para garantir o tratamento.

É importante que se registre algo mais acerca da postura da USP diante do deferimento massivo de pedidos de tutela antecipada:

A USP não é uma indústria química ou farmacêutica. Não tem condições de produzir a substância em larga escala, para atender às centenas de liminares judiciais que recebeu nas últimas semanas. Mais ainda, a produção da substância em pauta, por ser artesanal, não atende aos requisitos nacionais e internacionais para a fabricação de medicamentos (UNIVERSIDADE DE SÃO PAULO, 2015).

\footnotetext{
${ }^{3}$ Trata-se de um tipo de tumor cutâneo.

${ }^{4}$ Art. 24. "Estão isentos de registro os medicamentos novos, destinados exclusivamente a uso experimental, sob controle médico, podendo, inclusive, ser importados mediante expressa autorização do Ministério da Saúde" (BRASIL, 1976).
} 
Diante da comoção social e da provocação jurisdicional em torno do fornecimento da substância a quem reclama, bem como considerando a postura do Judiciário em muitos casos de deferir pedidos que obrigam a USP produzir e fornecer o produto sem que haja testes prévios que levem ao registro do produto como medicamento, se for esse o caso, está-se diante de implementação de política pública de saúde, por meio de medida estruturante.

Ou seja, os juízes não estão simplesmente aplicando normas vigentes a casos particulares, mas estão decidindo questão que envolve matéria sobre a qual não têm conhecimento técnico específico, que demanda intervenção e manifestação de entidades variadas, que deveria ser resolvida pelos outros poderes estatais e, por isso, questão complexa.

Carlos Alexandre de Azevedo Campos (2016) explica a medida ou "remédio estruturante":

[...], ante o reconhecimento da complexidade da situação, a Corte não mais se dirige a resolver problemas particulares, a assegurar direitos específicos de demandantes, e sim a proteger a dimensão objetiva dos direitos fundamentais em jogo. A Corte se encontra diante da figura do "litígio estrutural", que é caracterizado pelo alcance a número amplo de pessoas, a várias entidades e por implicar ordens de execução complexa. Para enfrentar litígio da espécie, juízes constitucionais acabam fixando "remédios estruturais", voltados ao redimensionamento dos ciclos de formulação e execução de políticas públicas, o que não seria possível por meio de decisões mais ortodoxas (CAMPOS, 2016).

O fato de o Estado não ter sido capaz, ainda, de fornecer um tratamento de saúde que resulte na cura do câncer e na diminuição das mazelas por ele causadas, os pacientes portadores da enfermidade, desesperados e à procura do menor sinal de milagre que possa existir, cobram do Judiciário uma resposta. E em virtude de mandamento constitucional, ele não pode esquivar-se de decidir.

Ocorre que a decisão não é simples, tampouco objetiva e sem desdobramentos às vezes indesejados. A decisão a ser proferida não pode afastar os que entendem do assunto. Ao contrário, eles devem participar de sua construção.

A evidência disso fica clara quando se constata que o Ministério da Saúde criou um comitê para estudar o assunto do ponto de vista sanitário. A Comissão Nacional de Ética em Pesquisa, do Conselho Nacional de Saúde (CNS), deverá emitir, em breve, parecer sobre projeto de pesquisa do governo do Estado de São Paulo sobre testes da substância em tela na 
cura do câncer (COMISSÃO..., 2016). Isso quer dizer que não se sabe se a "fosfoetanolamina" é um medicamento. Tampouco há qualquer comprovação de sua eficácia e eventuais efeitos colaterais.

Apesar disto, foi aprovado, no Senado Federal, o Projeto de Lei Complementar $n^{\circ}$ 03/2016, que autoriza pacientes de câncer a usarem a "fosfoetanolamina" sintética antes de seu registro na Agência Nacional de Vigilância Sanitária (Anvisa). Agora o projeto segue para a sanção presidencial.

Aqui nos interessa tratar a questão sob um enfoque bem específico: a imprescindibilidade da comparticipação na determinação e implementação de medida estruturante pelo Poder Judiciário.

\section{BREVES DIGRESSÕES ACERCA DAS DIRETRIZES DE COMPARTICIPAÇÃO DO NOVO CPC}

A partir do caso acima relatado, infere-se que a dinâmica processual descrita não observou as diretrizes de comparticipação dos sujeitos envolvidos para a construção conjunta da decisão. Isso porque o deferimento da liminar, sem prévia oitiva dos réus e de outros segmentos técnicos capazes interessados foi fator inviabilizador da sua implementação.

Não por outro motivo, a USP emitiu nota, na qual afirma não ter aparato técnico apto a suprir os mandados judiciais a ela impostos, seja pela ausência de testes comprobatórios dos efeitos regressivos da substância distribuída, seja pela falta de meios de produção bastantes para o atendimento aos pacientes em tratamento.

Nota-se a flagrante relevância de se franquear aos interessados no processo o contraditório efetivo, anteriormente às decisões, sempre que possível, a fim de que elas sejam efetivas. Mais que isso, o ponto nevrálgico é entender que a decisão judicial não deve ser resultado de entendimento solitário do julgador, mas deve ser construída por várias mãos.

Dessa forma, evita-se o dispêndio vão relativo aos trâmites processuais, bem como a frustração da expectativa das partes em decorrência de decisão natimorta, porquanto não passível de cumprimento. 
Com o fim de se entender a concepção comparticipativa defendida neste trabalho e que consta no NCPC (BRASIL, 2015), serão apresentados, ainda que em breves linhas, os dois grandes paradigmas da modernidade, o Liberal e o Social, que acabaram por impactar no sentido dado à Jurisdição de cada época.

Pois bem. O Estado Liberal, erguido sobre ideias iluministas, que tiveram como marco a Revolução Francesa, do final do século XVIII, é resultado de uma reorganização de poder e da ordem jurídica anterior, considerada "antigo regime". A busca por mais poder de decisão por parte dos indivíduos (conferido apenas aos ricos e pensadores), fez emergir o delineamento de um Estado de Direito.

Nas palavras de José Joaquim Gomes Canotilho (2003):

\begin{abstract}
Inicialmente, o Estado de direito começou por ser caracterizado em termos muito abstractos, como "Estado da Razão", "Estado limitado em nome da autodeterminação da pessoa". No final do século [XIX], estabilizaram-se os traços jurídicos essenciais deste Estado: o Estado de direito é um Estado liberal de direito. Contra a ideia de um Estado de Polícia que tudo regula e que assume como tarefa própria a prossecução da "felicidade dos súditos", o Estado de direito é um Estado liberal no seu verdadeiro sentido. Limita-se à defesa da ordem e segurança públicas ("Estado polícia", "Estado gendarme", "Estado guarda-nocturno"), remetendo-se os domínios econômicos e sociais para os mecanismos da liberdade individual e da liberdade de concorrência (CANOTILHO, 2003, p. 96-97).
\end{abstract}

O Estado Liberal e sua legislação primavam pela limitação do poder, obtida por meio da separação das funções estatais e pela observância do princípio da reserva legal.

Com base nesse prisma de análise, delineavam-se, em regra, legislações e sistemas processuais lastreados em princípios técnicos, agora liberais (liberalismo processual), quais sejam: a igualdade formal dos cidadãos, a escritura (mantida da fase pré-liberal) e, especialmente, o princípio dispositivo. Todos esses princípios técnicos buscavam a manutenção da imparcialidade e de um comportamento passivo por parte do juiz (NUNES, 2012, p. 73).

A partir daí o processo passou a ser tido como instrumento privado de resolução de conflitos, manejado exclusivamente para beneficiar as partes envolvidas. Nesse cenário o julgador era espectador da atuação de autor e réu. Ele somente aplicava as normas editadas pelo Legislativo. De acordo com Norberto Bobbio (2006):

[...], segundo Montesquieu, a decisão do juiz deve ser uma reprodução fiel da lei: ao juiz não deve ser deixada qualquer liberdade de exercer sua fantasia 
legislativa, porque se ele pudesse modificar as leis com base em critérios equitativos ou outros, o princípio da separação dos poderes seria negado pela presença de dois legisladores: o verdadeiro e próprio e o juiz que poria subrepticiamente suas normas, tornando assim vãs as do legislador (BOBBIO, 2006, p. 40).

Neste cenário maturavam as ideias de mínima atuação do julgador:

Ideias como a do princípio dispositivo, princípio da inércia, da iniciativa da prova exclusivamente às partes, do recurso voluntário, os pacta sunt servanda se baseiam na concepção de Estado liberal, em que o Estado é um mero espectador do duelo travado pelos cidadãos. [...] Prevaleciam os direitos individuais, também conhecidos como direitos de primeira geração (grifos do autor) (MADEIRA, 2008, p. 92-93).

A ideia de domínio do processo pelas partes e a escrituração dos atos procedimentais são herança do processo comum, anterior ao Estado de Direito, o qual trouxe consigo, de novo, o princípio da igualdade formal entre as partes, bem como o princípio dispositivo (ou seja, ao juiz não era dado manifestar-se de ofício). Neste contexto, enfim, as partes conduziam e dominavam o processo.

Considerando o aprofundamento das desigualdades sociais em razão da postura absenteísta do Estado Liberal, as novas concepções de capital e trabalho, a incapacidade daquele modelo de formular respostas aos anseios dos cidadãos, não mais satisfeitos com a diferença abissal entre classes, o ideal do Estado Liberal ruiu ainda no século XIX, e, com ele, as ideias liberais de processo.

O Estado Social surgiu lentamente e não sem críticas de uma sociedade baseada na meritocracia. No Estado Liberal importavam os direitos fundamentais burgueses de liberdade pessoal, política e econômica e os direitos sociais são a bandeira do Estado Social:

Se os direitos fundamentais são a garantia de uma sociedade burguesa separada do Estado, os direitos sociais, pelo contrário, representam a via por onde a sociedade entra no Estado, modificando-lhe a estrutura formal. A mudança fundamental consistiu, a partir da segunda metade do século XIX, na gradual integração do Estado político com a sociedade civil, que acabou por alterar a forma jurídica do Estado, os processos de legitimação e a estrutura da administração (BOBBIO; MATTEUCCI; PASQUINO, 2009, p. 401).

De se fazer referência às consequências do apreço por uma igualdade estritamente formal, tanto em nível social, quanto processual. Nas palavras de Paulo Bonavides (1993): 
Mas como a liberdade a que se arrima o liberalismo é apenas formal, e encobre, na realidade, sob o seu manto de abstração, um mundo de desigualdades de fato - econômicas, sociais, políticas e pessoais - termina "a apregoada liberdade, como Bismarck já o notara, numa real liberdade de oprimir os fracos, restando a estes, afinal de contas, tão-somente a liberdade de morrer de fome (BONAVIDES, 1993, p. 47).

Com o fim do pensamento liberal, a ideia de merecimento individual decai e a medida de justiça passa a depender cada vez mais da intervenção estatal. Com o início do século XX e o advento das duas guerras mundiais a atuação do Estado foi alargando-se cada vez mais. Se antes a lei era a única capaz de limitar a atuação do próprio Estado, o Legislativo foi perdendo espaço para os outros dois poderes (Executivo e Judiciário).

Neste cenário o julgador chama para si responsabilidades sociais, políticas e econômicas. Os seus poderes aumentam e em contrapartida as partes e seus advogados passam a ser, gradativamente, receptáculos da decisão judicial.

Se antes a igualdade formal atendia à ótica liberal, agora, no Estado Social, a igualdade material passou a ser buscada. $\mathrm{O}$ juiz passou a relacionar-se de forma paternalista com a parte hipossuficiente, como forma de corrigir a desigualdade social. Ocorre que essa postura intensamente intervencionista, diametralmente oposta ao que se via no processo liberal, acabou por subestimar a autonomia das partes, que se viram, cada vez mais, alijadas do processo decisório.

Além disso, o acesso à justiça passou a equiparar-se cada vez menos com um processo e provimento qualitativamente satisfatórios e cada vez mais a uma tutela jurisdicional final rápida, o que resulta em maior quantidade de decisões proferidas:

Este acesso à Justiça tenta equacionar as relações entre o processo civil e uma justiça social, entre igualdade jurídico-formal e desigualdade socioeconômica, partindo da concepção de Estado protetivo e de Bem-Estar Social. Ao visar a esses fins sociais, os processualistas começam a preocupar-se com a adequação da técnica processual a este novo panorama de análise e a construir procedimentos em que a cognição e decisão do juiz são majoradas (no caso brasileiro, cada vez menos controlados), possibilitando que uma intervenção mínima das partes possa chegar ao proferimento do provimento final, respondendo-se com menor custo e tempo possíveis às demandas no sistema judiciário (NUNES; TEIXEIRA, 2013, p. 31).

$\mathrm{O}$ acesso à justiça no Estado Social passou a ser visto como possibilidade do cidadão de fazer a sua demanda chegar ao conhecimento do julgador. O resultado da concentração de 
poderes nas mãos do juiz, bem como a desconsideração das partes e de seu papel no processo é uma decisão célere e automática.

Diante de tudo o que exposto até aqui, o que se percebe é que se de um lado o processo liberal primava pela autonomia e completa independência das partes em relação ao juiz; de outro, o processo social é marcado pelo reforço do papel do julgador, que ignora a participação das partes, e seus advogados, na preparação da decisão a ser proferida.

No atual cenário processual brasileiro, no mais das vezes, as partes são meros receptáculos da decisão solipsista e introspectiva de um julgador preocupado apenas em proferir mais decisões em menos tempo, para atingir metas estabelecidas por órgãos diretivos, completamente descompassadas com a realidade forense.

É possível identificar uma tensão entre os modelos processuais liberal e social. Os holofotes encontram-se ora nas partes, ora no julgador. Não há meio termo. O Código de Processo Civil de 1973 (BRASIL, 1973) foi editado sob nítidas influências sociais. Ao julgador é dado comandar solitariamente o destino das partes no curso do processo.

A evidente degradação atual à qual está submetida a Jurisdição faz buscar cada vez mais a quebra do protagonismo judicial, com fulcro no Estado Democrático de Direito:

\begin{abstract}
A degeneração de um processo governado e dirigido solitariamente pelo juiz [...], gerará claros déficits de legitimidade, que impedirão uma real democratização do processo, que pressupõe uma interdependência entre os sujeitos processuais, uma co-responsabilidade entre estes, e especialmente um policentrismo processual (NUNES, 2012, p. 195).
\end{abstract}

Não há qualquer legitimidade em um processo que prima pelo protagonismo das partes ou do julgador, de forma isolada, se considerar que todos os sujeitos processuais devem participar ativamente, simplesmente por serem interessados e destinatários do provimento final.

Se no Estado Liberal a autonomia das partes ditava as regras e no Estado Social o protagonismo do juiz se destacava, no Estado Democrático de Direito o processo deve ser um espaço discursivo comparticipativo de formação dos provimentos. Isso quer dizer que todos os sujeitos processuais têm voz na edificação da decisão final. É a democratização processual.

Por consequência, no Estado Democrático de Direito, é esta forma de estruturação procedimental que legitima o conteúdo das decisões 
jurisdicionais proferidas ao seu final, fruto da comparticipação dos sujeitos do processo (juiz e partes contraditoras), gerando a implementação técnica de direitos e garantias fundamentais ostentados pelas partes (DIAS, 2015, p. 134).

Com o intuito de se construírem provimentos adequados à melhor prestação jurisdicional é que o NCPC perfaz essa mudança paradigmática, em direção a um modelo cooperativo de processo, em que se erigem fundamentos de um sistema comparticipativo. Tudo isso com fincas a superar o modelo obsoleto vigente, em que prevalecem interesses não cooperativos dos envolvidos no deslinde da lide:

O sistema processual brasileiro é um ambiente no qual prevalecem os interesses não cooperativos de todos os sujeitos processuais. O juiz imerso na busca por otimização numérica de seus julgados e as partes (e seus advogados) no âmbito de uma litigância estratégica (agir estratégico) com a finalidade de obtenção de êxito. Esta patologia de índole fática não representa minimamente os comandos normativos impostos pelo modelo constitucional de processo, nem mesmo os grandes propósitos que o processo, como garantia, deve ofertar. Ao se partir dessa constatação cabe ao direito, dentro de seu pressuposto contrafático, ofertar uma base normativa que induza um comportamento de diálogo genuíno no qual estes comportamentos não cooperativos sejam mitigados. Isto induz à assunção do processo como um locus normativamente condutor de uma comunidade de trabalho, na qual todos os sujeitos processuais devam atuar em viés interdependente e auxiliar, com responsabilidade, na construção dos pronunciamentos judiciais e em sua efetivação (grifos dos autores) (THEODORO JÚNIOR et al., 2015, p. 69-70).

De posse dessa compreensão, dispõe o art. $6^{\circ}$ do Novo Código que "todos os sujeitos do processo devem cooperar entre si para que se obtenha, em tempo razoável, decisão de mérito justa e efetiva" (BRASIL, 2015). E mais, o art. 489 visa vincular o julgador ao que exposto pelas partes nos autos acerca da matéria discutida, devendo ele enfrentar os argumentos alinhavados por elas. $\mathrm{O}$ novo código processual pretende inquinar de nulidade as chamadas "decisões surpresa", que são aquelas proferidas pelo magistrado completamente à margem do que consta nos autos, sem proporcionar aos outros sujeitos processuais a oportunidade de se manifestar anteriormente.

Ao se lastrear o novo sistema processual na cooperação entre os sujeitos, não se pretende, inocentemente, que a solidariedade e altruísmo permeiem os atos processuais. Sustenta-se, na verdade, que a cooperação e a comparticipação sejam interpretadas como "corolário do contraditório, como garantia de influência" (THEODORO JUNIOR et al., 2015, p.71), na busca de uma decisão efetiva. 
Entenda-se efetividade nas palavras de José Joaquim Calmon de Passos (1999):

[...], não é o processo que reclama, enquanto tal, efetividade, mas sim a tutela prometida, o ordenamento como um todo sistemático, para cuja efetividade torna-se indispensável o processo de produção do direito, não qualquer processo, e sim o devido processo constitucional. A efetividade é a marca mesma do ordenamento jurídico. Sem ela, ele se desfuncionaliza e desqualifica. [...], por mais que se pretenda mascarar, a efetividade é algo de todo dependente do que precede adecisão, vale dizer, da cognição e da certificação que a antecederam. Nessas é que cumpre colocar ênfase (PASSOS, 1999, p. 34-35).

Desta forma, reclamar efetividade da tutela jurisdicional não implica focar na decisão proferida e sim no processo democratizante que a produziu. A comparticipação dos sujeitos na edificação do provimento é condição de alcance da efetividade exigida pelo ordenamento.

\subsection{DO CONTRADITÓRIO PRÉVIO À CONCESSÃO DE MEDIDAS LIMINARES NO NOVO CÓDIGO DE PROCESSO CIVIL}

Inicialmente, no que toca a este tópico específico, importa esclarecer que a medida liminar diz respeito não à natureza da decisão, mas ao momento processual em que ela é proferida, qual seja, o início do processo, sem citação ou oitiva da parte contrária (DIDIER JÚNIOR, 2015b, v. 2, p. 325). Como bem aponta Adroaldo Furtado Fabrício, (2000, p.763768), “a identificação dessa categoria não se faz pelo conteúdo, função ou natureza, mas somente pelo momento da provação.”

O Novo Código segue também esse raciocínio, a teor do disposto nos artigos 239, 300, $\$ 2^{\circ}$, 302, II e 311, parágrafo único. O art. 239, por exemplo, condiciona a validade do processo à citação do réu ou do executado, ressalvadas as hipóteses de indeferimento da petição inicial ou de improcedência liminar do pedido. O art. 302, II, por sua vez, trata da responsabilidade da parte pelo prejuízo decorrente da efetivação de tutela de urgência de caráter, obtida liminarmente, acaso não fornecidos os meios necessários para a citação do requerido em cinco dias. Já o art. 311, parágrafo único, elenca as hipóteses em que as decisões relativas a tutelas da evidência podem ser concedidas liminarmente (BRASIL, 2015). 
Percebe-se, assim, a possibilidade de concessão de medidas provisórias liminarmente, sendo tal adjetivo apenas uma característica cronológica, passível de aplicação para decisões de naturezas distintas, como são as tutelas de urgência e evidência, embora ambas provisórias.

De posse dessa informação, passa-se a esclarecer a nova estrutura das tutelas provisórias, que podem ou não ser liminares, conforme a seguir se explica. De acordo com o novo diploma processual civil, as únicas hipóteses possíveis de decisão liminar em tutelas provisórias são aquelas previstas no art. $300, \S 2^{\circ}$, que cuida das tutelas de urgência e no art.

311, II e III, que tipificam hipóteses de tutela da evidência satisfativa, aplicáveis tanto nos requerimentos antecedentes quanto incidentes (BRASIL, 2015).

A fim de melhor compreender tais hipóteses, insta consigná-las abaixo, nos moldes normativamente previstos, para facilitar a compreensão da matéria. Primeiramente, segue abaixo transcrita a hipótese de concessão de medida liminar relativamente a tutelas de urgência, ex vi do art. 300, $§ 2^{\circ}$ do NCPC:

Art. 300. A tutela de urgência será concedida quando houver elementos que evidenciem a probabilidade do direito e o perigo de dano ou o risco ao resultado útil do processo.

$\S \overline{2}^{\mathrm{O}}$ A tutela de urgência pode ser concedida liminarmente ou após justificação prévia (BRASIL, 2015).

Vislumbra-se, assim, que, uma vez preenchidos os requisitos para o deferimento da tutela provisória de urgência, quais sejam, a probabilidade do direito e o perigo de dano ou o risco ao resultado útil do processo, poderá ela ser concedida previamente à citação ou oitiva da parte contrária (liminarmente) ou após audiência de justificação prévia. Portanto, ainda que urgente a tutela pretendida, se houver qualquer dúvida a respeito do direito pleiteado antecipadamente, deve o juiz designar audiência de justificação prévia, com a finalidade de sanar dúvidas quanto ao preenchimento dos requisitos necessários ao deferimento da tutela.

No caso da tutela da evidência satisfativa, a decisão poderá ser liminar apenas nos casos infratranscritos, conforme previsão do art. 311, parágrafo único:

Art. 311. A tutela da evidência será concedida, independentemente da demonstração de perigo de dano ou de risco ao resultado útil do processo, quando: 


\section{$[\ldots]$}

II - as alegações de fato puderem ser comprovadas apenas documentalmente e houver tese firmada em julgamento de casos repetitivos ou em súmula vinculante;

III - se tratar de pedido reipersecutório fundado em prova documental adequada do contrato de depósito, caso em que será decretada a ordem de entrega do objeto custodiado, sob cominação de multa;

\section{[...] (BRASIL, 2015).}

Nesses casos, afasta-se a imprescindibilidade de instauração do contraditório, por já haver prova suficiente e hábil a ensejar a decisão liminar. Entende-se, pois, que a manifestação da parte contrária não teria o condão de infirmar os documentos acostados aos autos, nem tampouco as teses firmadas nos precedentes judiciais que, aliás, assumem relevância ímpar no novo sistema processual.

Todas as demais hipóteses de concessão liminar de tutelas provisórias dependerão do prévio estabelecimento do contraditório substancial junto ao réu, sob pena de cerceamento desproporcional ao seu direito de manifestação e defesa (DIDIER, JÚNIOR, 2015b, v. 2, p. 327. vol. II).

No caso dos incisos I e IV, do art. 311, a tutela da evidência não pode ser concedida liminarmente, por resultar "em grande parte do comportamento do réu ou das provas por ele produzidas e, por isso, o legislador não admite a possibilidade de provimento inaudita altera parte, somente podendo ser concedida depois de decorrido o prazo de resposta do réu" (GRECO, 2015, p.130-131).

Ressalte-se que o diferimento do contraditório, quando da concessão de medidas liminares, não fere essa garantia constitucional do jurisdicionado, porquanto seja esse momento apenas postergado. Segundo Fredie Didier:

Não há violação da garantia do contraditório na concessão, justificada pelo perigo, de tutela provisória liminar. Isso porque há uma ponderação legislativa entre a efetividade e o contraditório, preservando-se o contraditório para momento posterior. O contraditório, neste caso, é postergado para momento seguinte ao da concessão da providência de urgência. Como a decisão é provisória, o prejuízo para o réu fica aliviado. Nos casos de tutela provisória liminar de evidência, embora não haja perigo, a alta probabilidade de êxito da demanda é reconhecida como apta a mitigar o contraditório, postergando-o da mesma maneira (DIDIER JÚNIOR, 2015, vol. v. 1, p.83). 
Considerando que o contraditório é pressuposto de um processo democraticamente concebido, a sua função está ligada à participação efetiva das partes na construção do provimento. Essa comparticipação, elemento indispensável ao processo constitucionalizado, deve ser entendida sob o viés da garantia de influência e não surpresa (THEODORO JÚNIOR et al., 2015, p.92), também válida para as decisões liminares.

Destarte, no novo Código de Processo Civil, percebe-se que as decisões liminares são uma exceção à regra geral insculpida no art. $9^{\circ}$, parágrafo único, I e II, segundo a qual:

Art. 90 Não se proferirá decisão contra uma das partes sem que ela seja previamente ouvida.

Parágrafo único. O disposto no caput não se aplica: I - à tutela provisória de urgência;

II - às hipóteses de tutela da evidência previstas no art. 311, incisos II e III (BRASIL, 2015).

O juiz não pode decidir sem que às partes tenha sido oportunizada a manifestação pertinente. São exceções a essa previsão, no entanto, exatamente as hipóteses de concessão de medidas liminares acima descritas e transcritas, segundo o texto legal. Nota-se que o intento legislativo aponta para restrição da possibilidade do proferimento de decisões judiciais sem que se tenha estabelecido o contraditório prévio, evidenciando a ideia de que a colaboração entre as partes é crucial para que provimento seja efetivo. Não por outro motivo a previsão do art. $9^{\circ}$ integra o capítulo denominado "Das normas Fundamentais do Processo Civil", que regem todo o iter processual e das quais é exceção à concessão das liminares (BRASIL, 2015).

Se a oitiva das partes previamente à decisão constitui norma fundamental do Processo Civil, certamente há de ser pelo fato de o contraditório ser garantia de relevo à efetividade do processo. Assim, se o contraditório é realizado em atendimento às duas vertentes que o compõem, de garantia de influência e não surpresa, propiciando às partes um debate profícuo para a formação das decisões (contraditório dinâmico), diminui-se o tempo do processo, eis que se diminuem os recursos e a chance de provimento destes, viabilizando a executividade imediata das decisões proferidas (THEODORO JUNIOR et al., 2015, p.115).

O novo Código de Processo Civil, assim, busca pela efetividade dos provimentos. E, sobretudo quando se discute a concessão de liminares para a implementação de medidas 
estruturantes, que envolvem outras funções do Estado, bem como uma litigiosidade repetitiva, há que se buscar a oitiva dos interessados na matéria sobre que se decide, a fim de viabilizar o direito, através da cooperação entre os sujeitos processuais.

\section{DA COMPARTICIPAÇÃO COMO PRESSUPOSTO DE EFETIVIDADE DE MEDIDAS ESTRUTURANTES}

As medidas estruturantes foram assim cunhadas a partir da pesquisa desenvolvida por Owen Fiss, na Universidade de Yale, nos Estados Unidos, para tratar das structural injunctions (FISS, 1979), inauguradas com o caso Brown v. Board of Education of Topeka, decidido pela Corte de Warren $^{5}$, em 1954. A reforma estrutural proposta por Fiss é notadamente caracterizada pelo esforço de se atribuir significado aos valores constitucionais, no que tange ao funcionamento de organizações de grande porte, o que envolve consequências importantes na forma de construção e efetivação de tutelas jurisdicionais.

Com efeito, a atuação jurisdicional afeta a medidas estruturantes envolve, necessariamente, questões relacionadas ao ativismo judicial, como um modo proativo de interpretação da Constituição e que ocorre diante da falha legislativa e executiva, relativamente à observância dos direitos fundamentais. Essa forma de atuação:

Instala-se em situações de encolhimento do Poder Legislativo, onde ocorre um desajuste entre a esfera política e a sociedade, inabilitando que as demandas sociais sejam atendidas de maneira efetiva. Os problemas da sociedade atual requerem decisões com eficácia, o ativismo mostra-se um fenômeno positivo quando atende as necessidades da sociedade, o Poder Judiciário passa a ser a vis atrativa da qual em tempos outros o Executivo e o Legislativo seriam (PINHO; CÔRTES, 2014, p.231).

Tendo em vista, portanto, que as decisões que implantam medidas estruturantes envolvem uma atuação judicial proativa e, muitas vezes, atrelada à atuação dos outros Poderes do Estado, é importante que entre eles e as partes se estabeleça o diálogo necessário e hábil a que as medidas se concretizem.

\footnotetext{
${ }^{5}$ Earl Warren foi indicado pelo Presidente americano Dwight Eisenhower, em 1953 e presidiu a United States Supreme Court até 1969, sendo sua era marcada por importantes decisões relacionadas às liberdades civis dos cidadãos americanos, e, em especial, pelo julgamento do caso Brown v. Board of Education of Topeka.
} 
O contraditório entre os sujeitos processuais é determinante, inclusive, no momento anterior ao deferimento de liminares, pois da consulta às partes, entidades, pessoas especializadas ou à própria administração pública, pode resultar uma decisão mais efetiva. Nesse sentido, o órgão jurisdicional competente deve criar o espaço comunicativo entre os sujeitos, antes mesmo de fundamentar a decisão proferida:

A fundamentação da decisão antecipatória, embora não tenha de ser extensa, tem de ser completa. No Estado Constitucional, a direção do processo pelo juiz é pautada pela colaboração - o juiz é paritário na sua condução e assimétrico apenas quando prolata sua decisão. Isso quer dizer que o órgão jurisdicional, em face do dever de diálogo, tem o dever de responder a todos os fundamentos levantados pelas partes em seus arrazoados para tomar qualquer decisão (MITIDERO, 2011, p.91).

Superando-se, portanto, um direito processual atrelado a conflitos binários, voltado à resolução de conflitos individuais, e passando-se a um novo modelo em que se pleiteiam direitos fundamentais em face do Estado, de forma muito mais complexa, o julgador passa a ter de decidir de modo diverso.

Esse novo método decisório, porquanto envolva a polarização de inúmeros interesses diversos, pressupõe, para sua efetivação, a necessária comparticipação dos representantes desses interesses, na implementação do direito. Isso porque, sem tal ambiente dialógico, corre-se o sério risco de que as decisões, em especial as liminares, deferidas anteriormente ao contraditório, sejam inócuas.

Foi esse o desfecho provisório do caso relatado no primeiro item desse estudo, no qual a concessão de liminar para o fornecimento de substância usada para o tratamento do câncer ocorreu sem prévia manifestação da USP - Instituto de Química de São Carlos, responsável pela distribuição das cápsulas requeridas. Conforme descrito, em diversos autos distintos, a liminar pleiteada foi deferida, para determinar à USP o fornecimento da "fosfoetanolamina" aos pacientes em tratamento. Ocorre que, sem a oitiva da parte contrária, a distribuição da substância tornou-se inviável, já que os laboratórios que a produziam artesanalmente não têm estrutura capaz de absorver tamanha demanda. Ademais, sequer há estudos comprobatórios da eficácia do produto, razão por que seria razoável proceder-se à oitiva de especialistas capazes de atestar os reais efeitos decorrentes do seu uso. Por tal motivo, também, a USP, por meio da Portaria IQSC 1.389/2014, cessou a distribuição da substância, criando empecilhos de ordem técnica e estrutural ao fornecimento da droga (UNIVERSIDADE DE SÃO PAULO, 2014). 
O que se está buscando fazer, nesse momento, é pesquisar a fundo a substância, para saber seus reais efeitos, aguardando-se o pronunciamento da Comissão Nacional de Ética e Pesquisa, do Conselho Nacional de Saúde (CNS), sobre o tema. Verifica-se que os estudos necessários serão realizados em um contexto em que várias decisões já foram proferidas em favor dos pacientes, sem que se tenham informações técnicas concretas sobre o composto de que estão fazendo uso e sem que o distribuidor tenha aparato para fornecê-lo.

Dessa forma, a inviabilização de efetivação do direito concedido liminarmente poderia ter sido melhor administrada, se houvesse a oportunização do diálogo entre os sujeitos envolvidos nesse caso previamente ao deferimento da liminar.

Como no caso descrito no primeiro tópico do artigo, diversas são as vezes em que se deferem liminares para a implementação de medidas estruturantes, sem a oitiva da parte $e x$ adversa. Algumas das razões que justificariam tal comportamento seriam a invocação do direito fundamental à vida, à saúde ou à dignidade da pessoa humana, aliada ao fato de se tratar de questões complexas, que envolvem não só entes públicos, mas, muitas vezes, entidades ou pessoas especializadas nas temáticas relativas aos direitos perseguidos.

Todavia, se, ordinariamente, nos conflitos binários que envolvem primordialmente direitos particulares, a instauração do contraditório é de suma importância para que não se causem danos injustificados às partes, tanto mais relevo ganha a questão, ao se tratar de medidas estruturantes. Para tanto, há que se analisar na só a sua viabilidade técnica, mas também orçamentária e estrutural. Por isso, o diferimento do contraditório, no caso de concessão liminar de medidas estruturantes deve ser medida excepcional, sob pena de inoperância da decisão e inefetividade na implementação do direito declarado.

\section{CONCLUSÃO}

O caso estudado é apenas mais um dentre uma infinidade de questões submetidas à apreciação do Poder Judiciário, diante da ineficiência dos Poderes Executivo e Legislativo. Com a superação dos sistemas processuais liberais e sociais, que sustentavam um protagonismo ora das partes ora do julgador, o modelo constitucional de processo propõe um 
desenvolvimento da marcha processual sem protagonismos exacerbados, marcado, ao contrário, pela comparticipação e cooperação entre os sujeitos envolvidos.

Essa diretriz foi adotada no Novo Código de Processo Civil, que ressalta a importância da construção de um ambiente dialógico, para que as medidas pleiteadas se tornem exequíveis em maior medida. O corolário da participação endoprocessual se consubstancia no contraditório assegurado às partes, que assume ares de "Norma Fundamental do Processo Civill”. Tem-se, então, que as decisões judiciais não podem ser proferidas sem que às partes seja franqueada a manifestação no bojo dos autos.

A essa regra constitui exceção o deferimento de liminares. Para esse tipo de provimento, devem ser preenchidos os requisitos previstos em lei, e que, por sua natureza, autorizariam a decisão judicial antes da instauração do contraditório. Ressalte-se, contudo, que essa garantia, no caso do deferimento de liminares, fica apenas postergada para momento oportuno, em que à parte será dado falar nos autos.

Se o novo texto processual propõe, como norma fundamental, a vedação às decisões contrárias à parte não ouvida, há de ser pela efetividade que decorre do efetivo contraditório.

Em se tratando do deferimento liminar de medidas estruturantes, que, como dito, envolvem direitos e provimentos de cunho complexo, o contraditório deve ser expressão máxima da sua efetividade. Sem a oitiva dos interessados, o mandado judicial pode se tornar inócuo, como no caso apresentado, em que a determinação de distribuição gratuita da substância supostamente destinada à cura do câncer ficou prejudicada, tanto por fatores técnicos (ausência de comprovação da eficácia do produto), quanto estruturais (o laboratório do Instituto de Química de São Carlos não tinha condições de produzir a droga nas quantidades judicialmente impostas).

Conclui-se que a efetividade das medidas liminares concedidas a fim de que se implementem políticas públicas em geral é em forte medida condicionada ao contraditório prévio à decisão. A dialogicidade do ambiente processual é pressuposto para decisões que, de fato, consigam alcançar o fim a que se destinam, fazendo com que o Poder Judiciário não apenas reconheça o direito, mas esteja apto a efetivá-lo.

\section{REFERÊNCIAS}


ALVIM, J.E. Carreira. Comentários ao novo Código de Processo Civil: Lei 13.105/15. Curitiba: Juruá, 2015, v. I.

BOBBIO, Norberto. O positivismo jurídico: lições de filosofia do direito. São Paulo: Ícone, 2006.

BOBBIO, Norberto; MATTEUCCI, Nicola; PASQUINO, Gianfranco. Dicionário de política. v. 1. 13. ed. Brasília: UnB, 2009. v. I.

BONAVIDES, Paulo. Do estado liberal ao estado social. 5.ed. Belo Horizonte: Del Rey, 1993.

BRASIL. Lei n. 5.869, de 11 de janeiro 1973. Institui o Código de Processo Civil. Diário Oficial da União, Brasília, 17 mar. 2015. Disponível em: < http://www.planalto.gov.br/ccivil_03/leis/L5869compilada.htm>. Acesso em: 03 jan. 2016.

BRASIL. Lei n. 6.360, de 23 set. 1976. Dispõe sobre a Vigilância Sanitária a que ficam sujeitos os Medicamentos, as Drogas, os Insumos Farmacêuticos e Correlatos, Cosméticos, Saneantes e Outros Produtos, e dá outras Providências. Diário Oficial da União, Brasília, 23 set. 1976. Disponível em: < http://www.planalto.gov.br/ccivil_03/Leis/L6360.htm >. Acesso em: 04 jan. 2016.

BRASIL. Lei n. 13.105, de 16 março 2015. Código de Processo Civil. Diário Oficial da União, Brasília, 17 mar. 2015. Disponível em: < http://www.planalto.gov.br/ccivil_03/_ato2015-2018/2015/lei/113105.htm >. Acesso em: 03 jan. 2016.

BRASIL. Supremo Tribunal Federal. Medida cautelar na petição - Pet. 5828. Relator: Ministro Edison Fachin. Diário de Justiça Eletrônico, Brasília, 06 out. 2015. Disponível em: < http://www.stf.jus.br/portal/diarioJustica/verDiarioProcesso.asp?numDj=203\&dataPublicacao $\mathrm{Dj}=09 / 10 / 2015 \&$ incidente $=4862592 \& \operatorname{codCapitulo}=6 \&$ numMateria $=148 \& \operatorname{codMateria}=2>$. Acesso em: 02 jan. 2016. 
CAMPOS, Carlos Alexandre de Azevedo. "Estado de coisas inconstitucional” e litígio estrutural. Goiás: Academia Edu, 2016. Disponível em: < https://www.academia.edu/15685170/_Estado_de_Coisas_Inconstitucional_e_Lit\%C3\%ADgi o_Estrutural >. Acesso em: 02 jan. 2016.

CANOTILHO, José Joaquim Gomes. Direito constitucional e teoria da constituição. 7. ed. Coimbra: Almedina, 2003.

COMISSÃO de ética analisará testes com substância contra câncer. O Tempo, Belo Horizonte, 06 jan. 2016. (Saúde e Ciência). Disponível em: < http://www.otempo.com.br/interessa/sa\%C3\%BAde-e-ci\%C3\%AAncia/comiss\%C3\%A3ode-\%C3\%A 9 tica-analisar\%C3\%A1-testes-com-subst $\% \mathrm{C} 3 \% \mathrm{~A} 2$ ncia-contra-c\%C3\%A2ncer1.1207326 >. Acesso em: 07 jan. 2016.

DIAS, Ronaldo Brêtas de Carvalho. Processo constitucional e estado democrático de direito. 3. ed. Belo Horizonte: Del Rey, 2015.

DIDIER JÚNIOR, Fredie. Curso de direito processual civil: introdução ao direito processual civil, parte geral e processo de conhecimento. 17. ed. Salvador: Jus Podivm, 2015a. v.I.

DIDIER JÚNIOR, Fredie. Curso de direito processual civil: teoria da prova, direito probatório, ações probatórias, decisão, precedente, coisa julgada e antecipação dos efeitos da tutela. 10. ed. Salvador: Jus Podivm, 2015b. v. II.

FABRÍCIO, Adroaldo Furtado. Breves notas sobre provimentos antecipatórios, cautelares e liminares. In: MOREIRA, José Carlos Barbosa (Coord.). Estudos de direito processual em memória de Luiz Machado Guimarães. Rio de Janeiro: Forense, 1999.

FISS, Owen M. The forms of Justice. Harvard Law Review, n 93, Nov. 1979. Disponível em:

http://digitalcommons.law.yale.edu/cgi/viewcontent.cgi?article=2201\&context=fss_papers. Acesso em: 10 de janeiro 2016. 
GRECO, Leonardo. A tutela da urgência e a tutela da evidência no Código de Processo Civil de 2015. In: RIBEIRO, Darci Guimarães; JOBIM, Marcos Félix (Org.). Desvendando o novo CPC. Porto Alegre: Livraria do Advogado Editora, 2015. Cap. 8, p. 111-137.

LENHARO, Mariana. Cápsula da USP contra câncer não foi testada clinicamente. G1, São Paulo, 15 set. 2015. Ciência e Saúde. Disponível em: < http://g1.globo.com/ciencia-esaude/noticia/2015/09/pilula-da-usp-contra-cancer-nao-passou-por-testes-clinicosentenda.html>. Acesso em: 30 dez. 2015.

MADEIRA, Dhenis Cruz. Processo de conhecimento e cognição. Curitiba: Juruá, 2008. MENEGUELO, Renato. Efeitos antiproliferativos e apoptóticos da fosfoetanolamina sintética no melanoma B16F10. Escola de Engenharia de São Carlos. 2002. 134f. Dissertação (Mestrado) - Programa de Pós-graduação Interunidades em Bioengenharia, Universidade de São Paulo, São Carlos, 2002. Disponível: file://C:/Users/F\%C3\%A1bio\%20PC/Downloads/TDE_RenatoMeneguelo.pdf>. Acesso em: 03 jan. 2016.

MITIDIERO, Daniel. Tendências em matéria de tutela sumária: da tutela cautelar à técnica antecipatória. In: JAYME, Fernando Gonzaga; FARIA, Juliana Cordeiro de; LAVAR, Maira Terra (Org.). Processo civil: novas tendências: homenagem ao Ministro Sálvio de Figueiredo. Belo Horizonte: Del Rey, 2011. 728p.

NUNES, Dierle José Coelho. Processo jurisdicional democrático. Curitiba: Juruá, 2012. NUNES, Dierle; TEIXEIRA, Ludmila. Acesso à justiça democrático. Brasília: Gazeta Jurídica, 2013.

PASSOS, José Joaquim Calmon de. Cidadania e efetividade do processo. Revista Síntese de Direito Civil e Processual Civil. Porto Alegre, v. 1, n.1, p. 30-35, set./out. 1999.

PINHO, Humberto Dalla Bernardina de; CÔRTES, Victor Augusto Passos Villani. As medidas estruturantes e a efetividade das decisões judiciais no ordenamento jurídico brasileiro. Revista Eletrônica de Direito Processual - REDP. Rio de Janeiro, v. 13, n. 13, jul. 2014. Disponível em: $<$ http://www.epublicacoes.uerj.br/index.php/redp/article/view/11920/9333 >. Acesso em: 02 jan. 2016. 
PONTIFÍCIA UNIVERSIDADE CATÓLICA DE MINAS GERAIS. Pró-Reitoria de Graduação. Sistema Integrado de Bibliotecas. Orientações para elaboração de trabalhos científicos: projeto de pesquisa, teses, dissertações, monografias e trabalhos acadêmicos, conforme a Associação Brasileira de Normas Técnicas (ABNT), a American Psychological Association (APA) e o Comitê Internacional de Editores de Revistas Médicas (VANCOUVER). Belo Horizonte, 2015. Disponível em: < http://www.pucminas.br/documentos/orientacoes-abnt-apa-vancouver.pdf >. Acesso em: 02 jan. 2016.

SÃO PAUlO. Tribunal de Justiça. Processo - n. 1008889-52.2015.8.26.0566. Vara da Fazenda Pública. São Carlos, 25 ago. 2015. Disponível em:<https://esaj.tjsp.jus.br/cpopg/show.do?processo.codigo=FQ00015Q20000\&processo.foro $=566>$. Acesso em: 29 dez. 2015.

SÃO PAULO. Tribunal de Justiça. Suspensão de liminar ou antecipação de tutela n. 2194962-67.2015.8.26.0000. Relator: Desembargador José Renato Nalini, São Paulo, TJSP,

2015.

Disponível

em:

http://esaj.tjsp.jus.br/cpo/sg/search.do? conversationId=\&paginaConsulta=1\&localPesquisa.cd Local=1\&cbPesquisa=NUMPROC \&tipoNuProcesso=UNIFICADO\&numeroDigitoAnoUnifi cado $=219496267.2015 \&$ foroNumeroUnificado $=0000 \&$ dePesquisaNuUnificado $=2194962-$ 67.2015.8.26.0000\&dePesquisaNuAntigo=>. Acesso em: 02 jan. 2016.

Senado aprova uso da fosfoetanolamina, a pílula do câncer. Agência Senado, Brasília, 22 mar 2016. Disponível em: < http://www12.senado.leg.br/noticias/materias/2016/03/22/senadoaprova-uso-da-fosfoetanolamina-a-pilula-do-cancer >. Acesso em: 30 mar 2016.

THEODORO JÚNIOR, Humberto et al. Novo CPC Fundamentos e Sistematização Lei 13.105, de 16.13.2015. 2.ed.rev atual e amp. Rio de Janeiro: Forense, 2015.

THEODORO JÚNIOR, Humberto; OLIVEIRA, Fernanda Alvim Ribeiro de; REZENDE, Ester Camila Gomes Norato (coord.). Primeiras lições sobre o novo direito processual civil brasileiro (de acordo com o Novo Código de Processo Civil, Lei 13.105, de 16 de março de 2015). Rio de Janeiro: Forense, 2015. 
TOLEDO, Marcelo. Justiça libera suposta droga contra o câncer sem testes em humanos. Folha de São Paulo, São Paulo, 15 out. 2015. Disponível em: < http://www1.folha.uol.com.br/equilibrioesaude/2015/10/1694186-justica-libera-supostadroga-contra-o-cancer-sem-testes-em-humanos.shtml >. Acesso em: 04 jan. 2016.

UNIVERSIDADE DE SÃO PAULO divulga comunicado sobre a substância fosfoetanolamina: os fatos sobre a fosfoetanolamina: fosfoetanolamina não é remédio. São Paulo: USP, 13 out. 2015. Disponível em: <http://www5.usp.br/99485/usp-divulgacomunicado-sobre-a-substancia-fosfoetanolamina/>. Acesso em: 14 jan. 2016.

UNIVERSIDADE DE SÃO PAULO. Portaria IQSC 1.389/2014. Determina procedimentos administrativos quanto à produção, manipulação e distribuição de medicamentos e outros compostos no IQSC. São Carlos: Instituto de Química de São Carlos, 10 jun. 2014. Disponível em: < http://www5.iqsc.usp.br/files/2015/09/Portaria-distribuicao-demedicamentos.pdf>. Acesso em: 14 jan. 2016. 